\title{
Development of an I-deals Motivation and Management Measure
}

\section{P. Matthijs Bal}

Lincoln International Business School

University of Lincoln, Lincoln, United Kingdom

Department of Industrial Psychology and People Management

University of Johannesburg, Johannesburg, South-Africa

\begin{abstract}
Lien Vossaert
Department of Personnel Management, Work and Organizational Psychology

Ghent University, Ghent, Belgium
\end{abstract}

Correspondence should be addressed to: Matthijs Bal, Lincoln International Business School, University of Lincoln, Brayford Pool, Lincoln LN6 7TS, United Kingdom. Email: mbal@lincoln.ac.uk.

Acknowledgement: thanks to everyone who has been helpful in collecting the data for this study. 


\title{
Development of an I-deals Motivation and Management Measure
}

\begin{abstract}
This paper introduces three new dimensions to the idiosyncratic deals (i.e., i-deals) literature, and develops measures for these dimensions to broaden the scope of research on i-deals beyond i-deal timing and content. Based on four studies, the paper proposes and validates three new scales for measurement of i-deals motivations as well as management of i-deals. In Studies 1 and 2, the scales were developed and tested for their factor structure, reliability and discriminant validity. Studies 3 and 4 provided further evidence for the psychometric properties of the new i-deals measures and examined antecedents and outcomes of i-deal motivations and management. The results suggest that the three scales can be used to reliably measure i-deal motivations and i-deal management.
\end{abstract}

Keywords: Idiosyncratic deals, i-deals, management of i-deals, measure development, individualization of work arrangements. 


\section{Development of an I-deals Motivation and Management Measure}

During the past decennia a series of transitions has taken place challenging the long standing notion of standardization in HRM and giving rise to greater individualization and heterogeneity in the workplace (Bal \& Lub, 2016, Broschak \& Davis-Blake, 2006; Rousseau, Hornung, \& Kim, 2009). As a result, idiosyncratic deals (i.e., i-deals) have been a popular topic of recent research (Bal \& Rousseau, 2015; Liao, Wayne, \& Rousseau, 2016). I-deals are individualized agreements of individual employees with their organizations (Rousseau, Ho, \& Greenberg, 2006), which provide flexibility to employees and employers in regulating job content and conditions and steer away from a one-size-fits-all approach. Idiosyncratic deals have been defined by Rousseau (2005; Rousseau et al., 2006, p.978), as “voluntary, personalized agreements of a nonstandard nature negotiated between individual employees and their employers regarding terms that benefit each party”. Granting i-deals can help employers to accommodate the needs and ambitions of individual workers, by for example enabling an employee to follow a training which is not included in the standard training program of the organization, or allowing an employee to work from home while other employees are expected to come in to the office.

An increasing number of studies have been published on i-deals (Hornung, Rousseau, \& Glaser, 2008, 2009; Rousseau, Hornung, \& Kim, 2009). The primary focus of i-deals studies has been on the content of i-deals, or what type of i-deals employees have negotiated with their employer, such as flexibility and development i-deals (Hornung et al., 2008; Rosen, Slater, Chang \& Johnson, 2013). Moreover, the timing of i-deals has been found to differentiate effects of i-deals, namely whether employees have negotiated i-deals ex ante (before they were hired by their employer), or ex post (when they were employed at their organization; Rousseau et al., 2009). 
Despite the relevance of these scales for measuring the content and timing of $\mathrm{i}$-deals, there are also limitations. For instance, the meta-analysis of Liao et al. (2016) showed mixed effects of i-deals, with considerable variation in effect sizes of i-deals across studies. To be able to provide an explanation of these mixed findings, we argue that it is not merely the type of i-deal one negotiates with the employer that is relevant, but rather the reason why one initiates negotiation that will determine the effects of i-deals (Bal, 2017; Reif \& Brodbeck, 2014). The study of the motives people have for i-deal negotiation is important for several reasons. First, as people have different reasons for requesting an i-deal (Bal, 2017), the success of an i-deal depends on whether they fulfill the needs of an employee. Hence, it is important to assess the motivation of the i-dealer to be able to delineate the effects of i-deals. Moreover, motives may also explain why some i-deals are more strongly related to outcomes than others, despite having the same content or timing. Depending on the motives people have for negotiation, types of i-deals may be differentially related to outcomes. For instance, a development i-deal (e.g., additional training) may be negotiated from a perspective to enhance one's capabilities and career opportunities, or from a perspective to avoid becoming unemployable through outdated skills (Bal \& Jansen, 2016). These two motivations have different meanings, induce different emotions and hence, are likely to affect outcomes differently (Brockner \& Higgins, 2001). Finally, i-deals are assumed to have benefits for both employee and organization. This notion is still debated (Liao et al., 2016), and more knowledge on why people negotiate i-deals will further elucidate understanding of the benefits for both parties (Rousseau, 2005). Hence, it is important to investigate motives people have for negotiation, but also how i-deals are managed in the organization. In addition to the origins (i.e., motives) for i-deal negotiation, the management of i-deals is likely to influence the effects that i-deals have. However, so far reliable and valid measures are lacking (Bal \& Rousseau, 2015; Liao et al., 2016). 
This paper, therefore, presents the results of four studies of employees across various industries and countries in which we show both the reliability and validity of three new i-deal measures. We test the discriminant validity of the measures against existing i-deals measures, and we also test the convergent and criterion validity of the measures in relation to employee attitudes and other relevant constructs.

\section{Theoretical Background}

I-deals are different from psychological contracts. While the psychological contract has an inherent subjective nature, residing in the perceptions of an employee about mutual obligations, i-deals may be part of the psychological contract, but are about explicit agreements between employee and employer (Rousseau et al., 2006). I-deals can be categorized based on different elements (Rosen et al., 2013; Rousseau et al., 2009). First, ideals can be negotiated ex-ante or ex-post (Rousseau et al., 2009). Second, i-deals can be differentiated on the basis of their content, or what type of i-deal exactly is negotiated between employee and organization. Different measures have been developed pertaining to the content of i-deals. For example, Hornung et al. (2008) measured flexibility and development i-deals, and Rosen et al. (2013) developed a four-dimensional content typology, consisting of task and work responsibilities, schedule flexibility, location flexibility, and financial incentives. Overall, i-deals have been found to show positive relations with positive work-related attitudes, such as job satisfaction, affective commitment, OCB, and voice (Anand et al., 2010; Ng \& Lucianetti, 2016). However, meta-analytic evidence also shows that the correlations between i-deals and outcomes tend to be inconsistent (Liao et al., 2016).

\section{Introducing I-deal Motivation}

There is little known about the role of motives people have for i-deal negotiation. It is important, however, to study this, as previous research has shown that motives for negotiation determine work outcomes (Rioux \& Penner, 2001). People may have different motives for i- 
deal negotiation. After close scrutiny of the i-deals literature, we established two motives which are frequently described in relation to why people negotiate i-deals (Rousseau, 2005): on the one hand, people negotiate to i-deals for growth or to accumulate their skills, learning and development, and on the other hand, people may negotiate i-deals when they experience problems at work. For instance, Nauta and Van de Ven (2015) described how employees negotiate i-deals to develop knowledge or to decrease work demands. Moreover, Bal (2017), in a qualitative study on i-deal negotiation, found that workers either negotiate $\mathrm{i}$-deals to become more productive and efficient, and thus to grow in their working lives, or they negotiated i-deals to correct or solve a problem at work (such as a misfit between preferred and real working hours; see also Gascoigne \& Kelliher, 2018). While research beyond the ideals literature has established that people may also have other motives at work (such as greed or prosocial motives; Brett \& Thompson, 2016; Rioux \& Penner, 2001), not all motives pertain to i-deals, as i-deals are conceptualized to be mutually beneficial deals between an employee and the organization. For instance, greed may be a motivator for people to request an i-deal, but because i-deals are theorized to benefit both employee and organization, the employee has to acknowledge the organizational interest to grant an i-deal, through which the motives change (Rousseau, 2005).

Therefore, employees may have two primary motives to initiate i-deal negotiation. We differentiate between growth and accommodative i-deals. First, employees may start negotiating as they have needs to grow and develop themselves in their organization and their careers, and therefore negotiate growth $i$-deals. Growth i-deals are defined as i-deals which are negotiated by an employee to learn and develop themselves, either personally, in their organization or in their career, and to improve the fit between the preferences of an employee and the job. This also entails a perception in the employee of how one's job should look like 
in the future, and an active engagement to adapt one's job towards one's own needs (Bal, 2017).

Second, employees may start bargaining accommodative $i$-deals as they face problems at work or when they are confronted with a mismatch between themselves and their jobs as their job demands become too high. Accommodative i-deals are defined as i-deals negotiated by employees with the motive to repair or solve a mismatch in their jobs resulting from various circumstances (see also Kooij, Jansen, Dikkers, \& De Lange, 2014). Accommodative i-deals aim at solving a problem, and thus arise in situations where employees have difficulties in keeping up with job demands at work. Hence, accommodative i-deals are often triggered by external cues, such as a burnout (Gascoigne \& Kelliher, 2018), while growth ideals are often negotiated to promote one's career or learning.

While growth i-deals are negotiated by workers to learn or achieve upward movements of their careers and relative standing in the organization, accommodative i-deals are negotiated to repair a mismatch, or in other words, when employees experience that something is wrong in their job that needs to be solved or repaired. Both may enhance fit between the employee and the job, but the former focuses on expansion of action repertoires, responsibilities, and opportunities, while the latter is about potentially reducing demands or creating more flexibility to deal with demands. Hence, the distinction of i-deal motives are in line with regulatory focus theory (Brockner \& Higgins, 2001): growth i-deals may target at promotion goals, while accommodative i-deals result from a prevention focus, aimed at avoidance of negative outcomes, such as reductions of motivation and abilities.

I-deal motives are different from i-deal content (Rosen et al., 2013). The content of ideals refers to the actual resources that are negotiated by employees (Rosen et al., 2013), and denotes what is negotiated, and not why this has been negotiated as is the case with i-deal motives. In general, development i-deals will be more likely to be growth-orientated and 
flexibility i-deals will be more likely to be accommodation-orientated. Nevertheless, these measures also entail and mainly focus on the resources that are exchanged (tasks vs. work hours). By combining this in one measure it is impossible to separate the impact of the i-deal content from the motives people have for negotiation. When people have growth motives, both development (e.g., training to learn new skills) and flexibility (in working hours or location) can be negotiated. Similarly, when people have accommodative motives, they may also negotiate development (e.g., a course to balance work and life) and flexibility (e.g., reduction of working hours). Moreover, another distinction between content and motive pertains to development i-deals usually aiming at participation in training, courses or career progression (Hornung et al., 2008), while growth i-deals also contain aspects of personal growth and improvement of person-job fit, such as adaptation or expansion of tasks and ways of working. Hence, while growth and accommodative i-deals may be related to i-deal content, it is expected that they are empirically distinct from the content dimensions and can lead to different outcomes.

I-deal motives are also different from person-job fit, work-life balance and flexible work arrangements (Bal \& Jansen, 2016). I-deal motives differ from person-job fit, as the latter indicates either a subjective job attitude (i.e., someone perceives a fit with one's job) or a more stable objective phenomenon (i.e., a person's skills correspond with the abilities required for the job) (Kristof-Brown, Zimmerman \& Johnson, 2005). However, job fit does not explain how fit is constructed. I-deal motives refer to the motive for individualized negotiation as a way to adapt one's job circumstances which may subsequently lead to more job fit. Similarly, work-life balance may be an outcome of i-deal negotiation, but i-deal motives indicate the ways through which people may create greater work-life balance through individual negotiation with the employer about working conditions (Rousseau et al., 2006). Job fit and work-life balance may be created through HR policies and practices available to 
all employees, but also through i-deals (and i-deal motives). I-deals are not formal HR policies as they constitute individualized arrangements negotiated by employees (e.g., Bal, 2017). This also differentiates them from flexible work arrangements, which are generally available to all employees, while i-deals are individually negotiated (Bal \& Jansen, 2016). Moreover, flexible work arrangements are exclusively focused on flexibility at work, while ideal motives capture a much broader scope of arrangements (including development, and adaptation of workloads).

\section{Introducing I-deals Management}

This paper also introduces the concept of i-deal management. While many studies on i-deals have focused on the aftermath of successful i-deal negotiation (Liao et al., 2016), most of these studies investigated employee attitudes and behaviors as proposed outcomes of a successfully negotiated i-deal. Much less attention has been devoted to maintenance of the ideal itself, and whether or not employees and organization engage in monitoring and evaluation of the i-deal. I-deals by definition generate differentiation among employees in their work arrangements which requires good management of the deal to avoid perceptions of unfairness (Greenberg, Roberge, Ho \& Rousseau, 2004; Rousseau, 2005). In addition, i-deals can potentially generate negative consequences for other team members. For example, for work schedule i-deals, i-deal management will be important to monitor these alterations and avoid negative repercussions for customers or coworkers. Therefore, it is expected that when employee and manager actively manage the $\mathrm{i}$-deal, that is, to have frequent conversations about how the i-deal can be put into practice, and evaluate the state of the i-deal, employees will be more satisfied about their i-deals and engaged at work (Rousseau, 2005). Therefore, this study also develops a measure of i-deal management. 
In this study, we develop three new i-deals scales and conduct initial validity tests. Based on findings from previous research and interviews, items are developed for measuring accommodative and growth i-deals on the one hand and the management of i-deals on the other hand.

\section{Method}

\section{Procedure and Participants}

In 2012, 600 alumni of a psychology program at a Dutch university were invited to participate in an online study. In total 174 alumni started the questionnaire (29\%), and after deleting missing data, we retained 108 complete responses. The somewhat large proportion of missing data can be explained on the basis that many respondents dropped out in an early stage before starting the i-deals measures. As the study was part of a larger investigation of post-graduate experiences of alumni, the respondents had to complete a number of other scales, which led to some dropout during completion of the study. $81 \%$ of the respondents were female (mean age: 27 years; range 23-35 years). Participants worked on average 33 hours per week contractually. Average organizational tenure was 2.5 years. $40 \%$ of the participants worked in health care, $30 \%$ in education, $7 \%$ in the consulting industry, and $23 \%$ worked in other sectors, such as the financial industry and IT.

\section{Scale Development}

The authors developed a set of 25 items focusing on measurement of growth and accommodative i-deals, and i-deal management. All items were originally developed in Dutch, and subsequently translated into English. Items were developed based on a careful delineation of the construct (Hinkin, 1998) and drawing upon earlier qualitative research (Bal, 2017), and theoretical work (Nauta \& Van de Ven, 2015; Rousseau, 2005). No

\footnotetext{
${ }^{1}$ A previous version of this book chapter presented at a conference was obtained by the authors in preparation of this study.
} 
previous scales were available measuring these constructs, and the authors and three research assistants, who had accumulated expertise in the i-deal literature and development of new scales, drew upon quotes from the qualitative work published by Bal (2017) in developing the items. This ensured that the items were based on real life situations and observations (Rowan \& Wulff, 2007; Nielsen \& Abildgaard, 2012). Whilst creating scales that would reflect the three theoretical dimensions, the authors compared new items to existing scales (e.g., content and timing i-deals) to make sure they would represent different theoretical constructs.

For growth i-deals, we developed items specifically focusing on possibilities to learn and develop themselves, improve one's job fit, and increased challenges at work. For accommodative i-deals, we constructed items focusing on either reducing work demands, as well as maintaining the balance between work and private life. Subsequently, to measure ideal management, items were created that focused on the extent to which i-deals are evaluated, discussed, and monitored by the employee and the supervisor (Liao et al., 2016). Finally, we also created items relating to other aspects of i-deals, such as secrecy of i-deal making (Marescaux \& De Winne, 2015), and preferential treatment of employees by their supervisor (Rousseau et al., 2006). When incorporated in an exploratory factor analysis this can provide initial evidence for the discriminant validity of the proposed scales (Grover, 1991; Hinkin, 1998). This provided in total 25 items, which participants responded to, using a 5-point scale $(1=$ not at all; $5=$ totally agree $)$. The items were introduced through a short introduction of what idiosyncratic deals are (similar to Rosen et al., 2013). The statements reflect the extent to which the participant has voluntarily successfully negotiated individual agreements with their supervisor. The items were presented in complete randomized order.

\section{Validity Test Variables}

We also included two existing measures of timing of i-deals (Rousseau et al., 2009) to test for discriminant validity of the new measures. Ex-ante $(\alpha=.82)$ and ex-post $(\alpha=.74) i$ - 
deals were both measured using 2-item scales from Rousseau et al. (2009), measuring the extent to which workers had negotiated i-deals before they were hired (ex-ante) and after they were hired (ex-post) at their current organization $(1=$ strongly disagree; $5=$ strongly agree $)$.

\section{Results and Discussion}

\section{Exploratory Factor Analysis}

We conducted a factor analysis with oblique rotation in SPSS, to obtain factors that were empirically distinguishable yet were allowed to correlate, as we expected the new dimensions to be correlated with each other (Costello \& Osborne, 2005; Hinkin, 1998). Table 1 shows the results. While five factors could be identified with Eigenvalues greater than one, inspection of the scree plot, identified the break point after factor three. Hence, we focused on the first three factors (Costello \& Osborne, 2005). Items with factor loadings above .40 were retained, and items loading on multiple factors were deleted (Floyd \& Widaman, 1995).

As a result of this process, we found fifteen items that loaded on three factors in accordance with our expectations of obtaining three dimensions for growth i-deals, accommodative i-deals, and i-deal management. Two other items also loaded on growth ideals (see Table 1), but were theoretically different from the intended construct, as they measured whether coworkers were informed about i-deals, and whether the organization trusts the i-deal recipient in honoring the i-deals. While these two items may be indicative of the nomological network of growth i-deals, we deleted them because they were not measuring growth i-deals as defined above. The other eight items loaded on the fourth and fifth factor, which on the basis of the scree plot fell beyond the break point. Moreover, after inspection of these items, it was ascertained that these items did not correspond strongly with the newly constructed variables, and thus were deleted from further analyses.

We found evidence for five items for growth i-deals (Cronbach's alpha $=.89$ ), four for accommodative i-deals $(\alpha=.83)$, and six for i-deal management $(\alpha=.92)$. Subsequently, 
we performed the EFA with the 15 remaining items, producing three factors (on the basis of the scree plot), with all of the items having factor loadings higher than .50 on their respective dimensions. Furthermore, we also conducted an EFA with Varimax rotation, which yielded similar results, with the fifteen items loading on their respective factors, and no evidence for cross-loadings, or of any other of the ten additional items loading on the three dimensions.

We also added the two i-deal timing measures in the EFA. The factor analysis produced four factors, with the 15 new items loading on their respective factors (factor loadings $>.45$ ), and the additional four i-deal timing items loading on one factor (factor loadings $>.62$ ), with no cross-loading of these items on other factors. This provides initial support that these new items are empirically distinct from an existing i-deal measure. Table 2 shows the correlations among the three new i-deal dimensions and the two i-deal timing scales.

Insert Tables 1 and 2 here

The results of the first study show support for the existence of three new i-deals dimensions. The factor analysis provided support for the distinctiveness of these dimensions. To further test the validity, we conducted a second study in order to cross-validate the factor structure among a more heterogeneous sample of employees, and to test the distinctiveness of the new i-deals measures against content i-deals scales (i.e., Rosen et al., 2013).

\section{Study 2: Confirmatory Factor Analyses and Validity Tests}

This study aims to further establish validity for the three scales, and their divergence from the i-deals scale from Rosen et al. (2013). The latter constitutes of four dimensions related to the content of i-deals, namely task i-deals, flexibility i-deals, location i-deals and financial i-deals. We propose that a seven-factor model will fit the data best indicating that the three new scales constitute separate empirical constructs, and are empirically distinct 
from the four existing content measures. Therefore, additional evidence for the discriminant validity of the new i-deals scales is provided.

\section{Method}

\section{Procedure and Participants}

We collected data among a variety of employees working across different sectors in the Netherlands. Data were collected in spring 2013 through an online survey which was distributed by four research assistants, and spread across their networks with the specific aim to collect a diverse sample of employees working in organizations. We obtained 120 completed questionnaires. 63\% were female (average age: 31 years; range 20-64 years old). $77.5 \%$ had finished higher vocational training or a university degree, and $22.5 \%$ had finished high school or secondary education. Average organizational tenure was 4.7 years, and $26 \%$ had a supervisory position. $20 \%$ of the respondents worked in the hospitality industry, $14 \%$ in health care, $13 \%$ in education, $9 \%$ in the finance industry, and the other $44 \%$ worked in other industries.

\section{Measures}

Growth $i$-deals (five items), accommodative $i$-deals (four items) and $i$-deal management (six items) were measured using the fifteen items resulting from Study 1. Respondents received the same instruction as explained in Study 1. We also included the ideal measures of Rosen and colleagues (2013), consisting of four content dimensions to test the discriminant validity of the new measures against these existing scales (all items $1=$ strongly disagree; 5 = strongly agree). The Rosen et al. (2013) scales measure different content dimensions of ex-post negotiated i-deals. Task $i$-deals $(\alpha=.89)$ were measured using a six-item scale indicating the individualized agreements employees had negotiated with their supervisor regarding job-related tasks and flexibility in how the employee conducts the job. Flexibility $i$-deals $(\alpha=.70)$ were measured with three items indicating individualized work 
schedules. Location flexibility $i$-deals $(\alpha=.81)$ were measured with two items focused on the individualized agreements regarding completion of work outside the office. Finally, financial i-deals $(\alpha=.93)$ were measured with five items reflecting individualized compensation and pay arrangements.

\section{Results and Discussion}

\section{Confirmatory Factor Analyses}

We first performed a CFA using MPlus 7.4 (Muthén \& Muthén, 2015) on the three new measures. Covariances of items within each of the new i-deals dimensions were allowed to correlate, to account for their dependencies. Table three shows that the three-factor model (i.e., growth and accommodative i-deals, and i-deal management) obtained acceptable fit $\left(\chi^{2}\right.$ $=129.85, d f=75, p<.001, \mathrm{CFI}=.94, \mathrm{RMSEA}=.08, \mathrm{SRMR}=.06)$, with CFI beyond .90 (Meade, Johnson, \& Braddy, 2008). All items obtained significant and standardized loadings of .53 and higher on their respective factors. Moreover, the 3-factor model achieved a significant better fit than a 2-factor (growth and accommodative items loading on one factor) and 1-factor (all items loading on one factor) model. In line with recommendations of Meade et al. (2008), models were evaluated on the basis of CFI, whereby a change in CFI of .002 can be considered as a model improvement. The $.94 \mathrm{CFI}$ for the 3 -factor model was therefore deemed a significant better fitting model than the 2-factor model $(\mathrm{CFI}=.91 ; \Delta \mathrm{CFI}=.03)$ and the 1 -factor model $(\mathrm{CFI}=.76 ; \Delta \mathrm{CFI}=.18)$.

Subsequently, we included the four content i-deals in our CFA (Rosen et al., 2013), to ascertain the discriminant validity of the new measures (Bryant, King \& Smart, 2007). According to Shaffer, DeGeest, and Li (2016), discriminant validity can be tested using CFA, with a focus on $\triangle \mathrm{CFI}$ to test whether unconstrained models prove to be better than constrained models. Table 3 shows the results. First we ran a model using the seven proposed dimensions, and assessed model fit. The proposed model obtained an acceptable fit $\left(\chi^{2}=\right.$ 
$586.60, d f=401, p<.001, \mathrm{CFI}=.91, \mathrm{RMSEA}=.06, \mathrm{SRMR}=.07)$. All items obtained significant standardized loadings of .54 or higher. We compared this model to eight other models (See Table 3). We tested a model where growth and accommodative i-deals loaded on one factor, a model with flexibility and location i-deals loading on one factor (as they both denote types of flexibility i-deals), a model with growth and task i-deals loading on one factor (as both growth and task i-deals aim at development of the employee), a model with accommodative and flexibility i-deals loading on one factor (as accommodative i-deals often include enhanced flexibility at work), a model with all new dimensions loading on one factor (to test whether they are not one dimension vis-à-vis existing content measures), a model with all content $\mathrm{i}$-deals loading on one measure, a model with the new dimensions loading on one factor, and the content i-deals on one factor, and finally a model with all items loading on one factor. The baseline model including the seven dimensions produced a better fit than all the alternative models. The CFI of .91 for the 7-factor model was superior to all other models (Meade et al., 2008; Shaffer et al., 2016). Hence, the results indicate that the current factor structure produced the best fit to the data, and that the new i-deals dimensions are empirically distinct from existing content dimensions (Rosen et al., 2013).

Insert Tables 3 and 4 here

Table 4 shows the correlations among the variables under study. Task i-deals and flexibility i-deals were both positively related with all i-deals dimensions ( $r$ 's ranging between .19 and .53). Location i-deals were positively related to growth i-deals $(r=.26, p<$ $.01)$, and to i-deal management $(r=.24, p<.01)$. Financial i-deals were unrelated to growth or accommodative i-deals, but were positively related to i-deal management $(r=.39, p<.01)$. Finally, growth i-deals were positively related to accommodative i-deals $(r=.59, p<.01)$, and to i-deal management $(r=.45, p<.01)$, and accommodative i-deals were also positively 
related to i-deal management $(r=.48, p<.01)$. In sum, Study 2 showed that the factor structure of Study 1 could be replicated in a CFA, bolstering our conclusion that the three ideals dimensions are valid and reliable. The three new factors represent empirically distinct factors, and were also empirically distinct from content i-deals measures (Rosen et al., 2013), thereby showing discriminant validity of the measures. Furthermore, we also found meaningful correlations between the two sets of i-deals measures. The next step of testing our new measures is showing convergent validity.

\section{Study 3: Convergent Validity of I-deals Motivation and Management}

The third study comprises CFAs and tests for convergent validity of the three new scales (Hinkin, 1998). We propose that in general, growth i-deals will be positively related to job attitudes, and in particular work engagement. When employees are motivated to grow in their organization, and consequently obtain i-deals, job design theory (Hornung et al., 2008) would predict that they will be more likely to enjoy their jobs. Moreover, we expect that growth i-deals will also be related to lower turnover intentions, as for those employees who have growth motives negotiating i-deals may also create new possibilities for learning within their organization, and hence, induce the motivation to stay in the organization (Kroon et al., 2015). We expect the relationships of accommodative i-deals and i-deal management with work engagement and turnover intentions to be less straightforward. Accommodative i-deals are usually negotiated when employees experience problems at work (Bal, 2017), and therefore it is less evident that they experience higher engagement or lower turnover intention as a result of having negotiated an i-deal. It may be that these people just maintain their level of engagement and intentions to remain in the organization through accommodative i-deals and therefore, positive relationships may not occur. Some employees who negotiate accommodative i-deals may also struggle with coping well at work, and therefore, it may also be that even though they have negotiated such i-deals, they may still look for other jobs with 
either lower job demands or working hours. Therefore, the relationships between accommodative i-deals and turnover intention are somewhat speculative. Similarly, i-deal management may motivate employees, through facilitating the transfer from an agreement into daily working life, and therefore may contribute to higher engagement and lower turnover intention. However, i-deal management may also be related to employee monitoring and managerial control (Martin \& Freeman, 2003), which may create negative feelings, and lower engagement and higher turnover intention. Hence, we do not expect significant relationships between accommodative i-deals, i-deal management and engagement and turnover intention.

Finally, we expect that i-deal motives will be related to autonomy. Autonomy at work indicates the possibility for employees to have valuable input into how and when the job is conducted, and allows the workers to exert control over the key aspects of a job. As i-deals are a form of decentralized decision making for employees, it is likely that employees who negotiate i-deals to grow or solve a problem also create more freedom and control over their work, and thus more job autonomy. We expect this to be the case primarily for i-deal motivation, rather than i-deal management, which may be associated with greater levels of managerial control, and therefore less autonomy for workers.

In addition to testing the convergent validity of the new measures in relation to potential outcomes, we will also focus on a predictor of i-deal motivation and management to broaden the nomological network. In particular, we test whether transformational leadership is related to the new i-deal measures. Transformational leadership is theoretically important in relation to i-deals (Hornung et al., 2009), as leaders who are so-called transformational are able to inspire and motivate their employees, but more importantly, treat their employees as individuals rather than as mere resources who are exploited by the organization to achieve its aims. Through individual consideration, transformational leaders acknowledge differences 
between employees in needs and engage in coaching and mentoring to meet those needs (Avolio \& Bass, 1995). As i-deals can help meet individual needs (Hornung, Rousseau, Glaser, Angerer, \& Weigl, 2011) and are a signal from the organization that it cares about the career advancement and well-being of the individual employee (Ho \& Kong, 2015), it can be expected that transformational leaders will grant more growth and accommodative i-deals and in parallel also adopt more i-deal management. Therefore, we propose that the three new i-deal dimensions relate positively to transformational leadership.

\section{Method}

In summer 2013, an online survey was sent to a wide range of employees within the Netherlands. In total, we obtained 153 completed responses to the questionnaire (which entails a $51 \%$ response rate). $56 \%$ were women and $71 \%$ was between $25-34$ years old. $16 \%$ worked in education, $7 \%$ in health care, $7 \%$ in IT, $5 \%$ in marketing, and the other $65 \%$ worked in a wide variety of sectors.

\section{Measures}

The three new $\mathrm{i}$-deal dimensions growth $i$-deals $(\alpha=.78)$, accommodative $i$-deals $(\alpha=$ $.89)$, and $i$-deal management $(\alpha=.86)$ were measured using the same fifteen items as in the previous studies. Work Engagement $(\alpha=.89)$ was measured with the nine-item UWES scale (Schaufeli \& Bakker, 2004), using a six-point scale (1 = never; 6 = daily). Turnover intentions $(\alpha=.86)$ were measured with a four-item scale from Farh, Tsui, Xin and Cheng $(1998 ; 1=$ strongly disagree, $7=$ strongly agree $)$. Autonomy $(\alpha=.93)$ was measured using three items from Breaugh (1989; 1 = strongly disagree; 7 = strongly agree). Transformational Leadership $(\alpha=.88)$ was measured using twelve items from Bass and Avolio (1997; $1=$ strongly disagree, $5=$ strongly agree), including the dimensions inspirational motivation, intellectual stimulation, and individual consideration.

\section{Results and Discussion}


We first performed a CFA on the i-deal dimensions using MPlus. The three new dimensions were first tested as a 3-factor model, and compared to a 2-factor model (where growth and accommodative i-deals were constrained to load on one factor), and a 1-factor model (where all items loaded on a single i-deal dimension). Covariances of the items within each new i-deal dimensions were allowed to correlate, to account for their dependencies.

Table 3 (lower part) shows the results of the model testing. The table shows that the baseline model, including the three proposed dimensions, obtained the best fit to the data $(\mathrm{CFI}=.92)$, and fitted better than the other models (2-factor model $\Delta \mathrm{CFI}=.03$; 1 -factor model $\Delta \mathrm{CFI}=$ .13; Meade et al., 2008). All standardized factor loadings of the items on their factors were significant and above .43 . Hence, this provides further evidence of the factor structure of the three dimensions.

Table 5 shows the correlations between the different dimensions, and Table 6 shows the results of hierarchical regression analysis. These showed that growth i-deals were in particular related to work engagement $(\beta=.46, p<.001)$, turnover intention $(\beta=-.29, p<$ $.05)$, and job autonomy $(\beta=.50, p<.001)$, while accommodative $\mathrm{i}$-deals were unrelated to work engagement $(\beta=.01, n s)$, turnover intention $(\beta=.00, n s)$, and autonomy $(\beta=-.04, n s)$. I-deal management was unrelated to work engagement $(\beta=-.11, n s)$, and turnover intention $(\beta=.08, n s)$, but negatively to autonomy $(\beta=-.28, p<.01)$. This supports our propositions, showing that in particular growth i-deals were positively related to engagement and autonomy, whilst being negatively related to turnover intentions. We also inspected correlations of the three i-deals dimensions with transformational leadership.

Transformational leadership was positively related to growth i-deals $(r=.57, p<.001)$, accommodative i-deals $(r=.45, p<.001)$, and to i-deal management $(r=.39, p<.001)$, thereby supporting our expectations.

Insert Tables 5-6 here 
Study 3 showed that the factor structure of the new i-deals dimensions could be replicated, and produced valid and reliable dimensions. Hence, study 3 bolstered our findings from the previous two studies. Moreover, we were also able to show convergent validity, by showing that transformational leadership was related to all of the new dimensions. Finally, the regressions showed that in particular growth i-deals were related to engagement and turnover intentions, as compared to accommodative i-deals and i-deal management. These findings are in line with the dominant focus in i-deals research on development i-deals (Anand et al., 2010), based on the notion that i-deals aimed at growth and advancement of one's position in the organization and one's career is most likely to have beneficial effects on job attitudes and behaviors. Furthermore, we found that growth i-deals were positively related to autonomy, while i-deal management was negatively related to autonomy. It may be that growth i-deals facilitate the employee more freedom in making decisions at work $\mathrm{CWu}$, Griffin, \& Parker, 2015). However, we also found that when i-deals are actively managed, it is related to lower perceptions of autonomy. It may be that when employees feel that their ideals are controlled by their organization through strict management (including being monitored and controlled), they feel their autonomy hampered (Martin \& Freeman, 2003). The final step of developing the measures is testing for predictive validity.

\section{Study 4: Criterion Validity of I-deals Motivation and Management}

The final study aims to assess the predictive validity of the new measures. More particularly, while the previous studies have shown that the new measures are valid and reliable, it has yet to be established whether they relate to outcomes over time. Hence, we conducted a two-wave longitudinal study to assess whether i-deal motivation and management are related to the outcomes. We adopt the variables from the previous study, except for autonomy, and also add a number of theoretically relevant predictors and 
outcomes. This enables us to further establish the nomological network of the new i-deals scales.

First, as antecedents of i-deal motivation and management, we include transformational leadership and career orientation. Similar to study 3 , we expect transformational leadership to be positively related to all three i-deals dimensions. Moreover, we also included career orientation (Allen \& Ortlepp, 2012) indicating the importance one attaches to the career (vs. family life). We expect that workers who have a strong career orientation, will be more likely to seek growth i-deals rather than accommodative i-deals ( $\mathrm{Ng}$ \& Lucianetti, 2016) and initiate i-deal management, to ensure that i-deals are materialized in the workplace. People high on career orientation prioritize their careers over other domains in their lives, and are prone to invest time and energy into development of their career. Hence, they will be likely to initiate growth i-deal negotiation, while they may be less likely to negotiate accommodative i-deals, as the latter may impede their chances for career development and success (Bal, 2017).

Second, we test predictive validity of the i-deal measures in relation to four possible outcomes. Similar to Study 3, we expect that growth i-deals will be positively related to work engagement and negatively to turnover intention. In addition to these two outcomes, we also include initiative taking (Morrison \& Phelps, 1999). As growth i-deals aim at advancement of the employee in the job and the career, it is likely that as a result, the employee feels more capable and stimulated to seek additional challenges at work, thereby engaging in taking initiative to improve functioning of the workplace. We also expect a positive relationship between growth i-deals and i-deal satisfaction, which is included as final outcome. For accommodative i-deals, we expect that they are not necessarily related to more initiative taking, as they aim at problem solving rather than the creation of new challenges. Accommodative i-deals, however, may help the employee to become more satisfied with 
their job due to for example a negotiated reduced workload that helps the employee find a balance between his work and his career and as such contribute to i-deal satisfaction (Bal, 2017).

\section{Method}

\section{Procedure and Participants}

On April 25-26, 2016, a survey was distributed among a sample of 500 workers who had registered at the website Prolific Academic (prolific.ac). Only participants who were employed at an organization were selected. From June 3-12, 2016, 427 respondents took part (85\% response rate) in the second wave. $61 \%$ of the respondents were from the UK, $20 \%$ from the US, and the other 19\% from various countries across Europe and Asia. 85\% had permanent contracts with an employer, and they worked for various industries, including IT (14\%), education (13\%), engineering (8\%), and retail (8\%). $50 \%$ were male, and the mean age was 36 years old.

\section{Measures}

The three $\mathrm{i}$-deal dimensions growth $i$-deals $(\alpha \mathrm{T} 1=.85, \mathrm{~T} 2=.88)$, accommodative $i$ deals $(\alpha \mathrm{T} 1=.86, \mathrm{~T} 2=.91)$, and $i$-deal management $(\alpha \mathrm{T} 1=.89, \mathrm{~T} 2=.92)$ were measured at $\mathrm{T} 1$ and $\mathrm{T} 2$ using the same fifteen items as in the previous studies. Transformational Leadership $(\alpha \mathrm{T} 1=.93)$ was measured using the same twelve items as in Study 3. Career Orientation $(\alpha \mathrm{T} 1=.91)$ was measured with 11 items from the Allen and Ortlepp (2012) Career Salience Questionnaire, indicating the importance of one's career.

Work Engagement $(\alpha \mathrm{T} 2=.95)$ was measured at T2 with the nine-item UWES scale (Schaufeli \& Bakker, 2004; 1 = never; $7=$ daily). Turnover intentions $(\alpha$ T2 = .91) was measured with the 5-item measure from Wayne et al. (1997). Initiative Taking $(\alpha$ T2 $=.91)$ was measured with the 10-item measure from Morrison and Phelps (1999). Satisfaction with I-deals $(\alpha \mathrm{T} 1=.93)$ was measured at $\mathrm{T} 1$ due to space constraints in the $\mathrm{T} 2$ measurement. 
Three items were used to measure i-deal satisfaction: "I am satisfied with the i-deals I have been able to negotiate with my employer", "My negotiated i-deals have brought me happiness at work", and "My job has become more enjoyable as a result of the i-deals I have negotiated". We also measured Ex-ante $(\alpha=.83)$ and Ex-post I-deals $(\alpha=.92)$ at T1 with the items from Rousseau et al. (2009) as control variables.

\section{Results and Discussion}

Table 7 shows the correlations, Table 8 shows the results of the hierarchical regression analyses for the predictors of $\mathrm{i}$-deals, while Table 9 shows the regression results for the outcomes of i-deals. Test-retest reliability was calculated using the correlations over time, which show that growth i-deals T1-T2 were correlated .74, accommodative i-deals T1$\mathrm{T} 2$ were correlated .71, and i-deal management T1-T2 were correlated .73, indicating high test-retest reliability over time.

Cross-lagged relationships of predictors at $\mathrm{T} 1$ with outcomes at $\mathrm{T} 2$ were tested (except for satisfaction with i-deals). Transformational leadership T1 was positively related to both growth i-deals T2 $(\beta=.33, p<.001)$, accommodative i-deals T2 $(\beta=.32, p<.001)$, and to $\mathrm{i}$-deal management $\mathrm{T} 2(\beta=.24, p<.001)$, providing additional support for our expectations. We also found career orientation $\mathrm{T} 1$ to be positively related to growth i-deals $\mathrm{T} 2(\beta=.18, p<.001)$ and $\mathrm{i}-$ deal management $\mathrm{T} 2(\beta=.19, p<.001)$, but not to accommodative i-deals T2 $(\beta=.09, n s)$. In a next step, we regressed the outcome variables on the new dimensions at $\mathrm{T} 1$, including the i-deal timing control variables. For work engagement $\mathrm{T} 2$, we found growth $\mathrm{i}$-deals $\mathrm{T} 1$ to be positively related $(\beta=.28, p<.001)$, as well as $\mathrm{i}$-deal management $\mathrm{T} 1(\beta=.16, p<.05)$. Accommodative $\mathrm{i}$-deals $\mathrm{T} 1$ were not related to work engagement T2 $(\beta=-.10, n s)$. Surprisingly, none of the new i-deal dimensions were related to turnover intention T2 (growth i-deals T1: $\beta=-.11, n s ;$ accommodative $\mathrm{i}$-deals T1: $\beta$ $=.04, n s ; \mathrm{i}$-deal management T1: $\beta=-.05, n s)$. Growth $\mathrm{i}$-deals $\mathrm{T} 1$ were positively related to 
initiative taking T2 $(\beta=.26, p<.001)$. Accommodative i-deals T1 $(\beta=-.13, n s)$ and i-deal management T1 $(\beta=.06, n s)$ were unrelated to initiative taking T2. Finally, both growth ideals T1 $(\beta=.19, p<.001)$, and accommodative i-deals T1 $(\beta=.13, p<.05)$ were positively related to satisfaction with i-deals $\mathrm{T} 1$, but $\mathrm{i}$-deal management $\mathrm{T} 1$ was unrelated $(\beta=-.10, n s)$.

Insert Tables 7-9 here

The results from Study 4 show that the i-deal dimensions could be replicated in an international sample of workers, and reliable dimensions were obtained. Moreover, using a two-wave longitudinal design, we were able to assess test-retest reliability of the new measures, and we found them to be reliable over time. Moreover, we also tested the relationships of the nomological network of the i-deal dimensions over time. In particular, we found evidence that transformational leadership is important for all i-deal dimensions, while employees with a strong career orientation are likely to negotiate growth i-deals and to manage i-deals as well. Moreover, the study showed that growth i-deals are related to more work engagement, initiative taking, and satisfaction with i-deals over time. Accommodative i-deals were only related to satisfaction with i-deals, while i-deal management was positively related to work engagement over time. In all, these results show that the strongest relationships were found for growth i-deals, which may be explained by the motivational potential of these types of i-deals for growth and development of the employee in the organization (Hornung et al., 2008). Less direct evidence was found for accommodative ideals and i-deal management, whose potential positive effects may occur for alternative outcomes or under certain conditions, such as supportive climates or supervisors (Bal et al., 2012).

\section{General Discussion}


The current study aimed to broaden the scope of the i-deals concept, and introduced two new aspects to i-deals research: i-deal motivation and i-deal management. We distinguished two broad types of i-deal motives: growth and accommodative (Bal, 2017; Nauta \& Van de Ven, 2015). Furthermore, we introduced the concept of i-deal management, which refers to the extent to which employee and supervisor actively monitor and evaluate negotiated i-deals in the workplace. Through introducing these two new concepts in the ideals literature, we expand the breadth of research that can be conducted on i-deal dynamics in the workplace (Rousseau, 2005). It is not only important to assess whether people have successfully negotiated an i-deal, but also why they have initiated negotiation.

Moreover, future researchers may also incorporate measures of i-deal management, to assess the extent to which i-deals are actually discussed and evaluated. This may be particularly important when employees do not actually experience the benefits of i-deals. When i-deals either do not fit with daily work practices (e.g., when a flexible working hours i-deal does not fit with the real working hours), or when employees refrain from using i-deals in the workplace (e.g., as they may perceive to be treated more favorably in comparison to others for no good reason), i-deals may actually lose their beneficial nature. Appropriate ideal management may be important to increase the legitimacy of i-deals in the workplace (Rousseau, 2005), as individualization of work arrangements creates differences in working conditions and rewards among employees within the same organization. Therefore i-deal management is important to reduce perceptions of unfair treatment within working groups (Greenberg et al., 2004), and to enhance legitimacy of i-deals, not only for employees and coworkers, but as an organizational practice existing in organizations beyond standardized HR practices available to a wider set of employees (Bal \& Rousseau, 2015). However, the results also showed that i-deal management can be a 'mixed blessing', as they may relate to lower autonomy at work, and more monitoring and control of the employee by supervisors. 
This may have important ramifications for the i-deals literature, and hence more research is needed to further investigate how i-deal management affects i-deals and employees.

There was little evidence for direct relationships of accommodative i-deals with outcomes. There may be at least three contexts which may enhance the value of accommodative i-deals. First, accommodative i-deals may be more likely to be negotiated by particular groups of workers, such as older workers (Bal et al., 2012). As older workers may struggle with balancing the demands of their jobs and their declining physical abilities to conduct their work, they may have higher needs for accommodative i-deals. Second, the relationships of accommodative i-deals may not always be aimed at improving motivation, but may also be negotiated to maintain motivation. In other words, employees who are struggling to conduct their work and to remain in their jobs, may negotiate accommodative ideals to prevent burnout and absenteeism. Thereby, they maintain their current functioning at work, and therefore prevent a decrease of their motivation. It is therefore important that intrapersonal research is conducted to test the effects of i-deals within persons over time. Finally, accommodative i-deals may be related to other outcomes which have not been included in the current study, such as well-being and healthy aging. Therefore, future research may also incorporate other outcomes following accommodative i-deals.

Furthermore, while the reasons for negotiation may determine the actual outcome in terms of benefits for the employee and the organization, it is also dependent upon how the ideal is managed. I-deal management is related to the extent whether goals are met as a result of i-deal negotiation. However, i-deal management may be a predictor of meeting goals rather than be a central part of it. Moreover, as goals may shift over time, i-deal management may be necessary to ensure that both employee and management are aware of how i-deals are transferred into the workplace as well as whether i-deals actually (need to) change in content 
over time. It may therefore be that i-deal management has a more complex role in the process of translating i-deals into practice.

In sum, future research may further unravel the role of i-deal motivations and management in how they are influenced by antecedents, such as various types of proactive behaviors, negotiation skills, gender, and employee goals (Liao et al., 2016; Ng \& Lucianetti, 2016), as well as how they relate to outcomes, including individual-level, group-level, and organizational level outcomes (Liao et al., 2016), and finally how they interact with other ideal dimensions.

\section{Limitations}

The first three studies on which the development of the new scales was based, were cross-sectional studies of employees in the Netherlands. Hence, it is impossible to allow for causal conclusions about the new dimensions and the relationships with antecedents and outcomes. While the fourth study was longitudinal, it is important to investigate further dynamics of i-deals over (longer periods of) time. Second, in line with most research on ideals, we measured i-deals motivation and management from the perspective of the employee. Future research might also benefit from investigating i-deals from the perspective of employers and other relevant stakeholders, such as supervisors and coworkers. Finally, another limitation pertains to the context of our studies, which were primarily based in the Western world. In other countries across the world, there may be other dominant cultural norms about negotiation (Rousseau, 2005). Future research may shed more light upon the cross-cultural differences in negotiation of i-deals.

\section{Summary and Conclusions}

This paper presented four studies in which three new i-deal scales were introduced focused on measurement of i-deal motivation and i-deal management. Through showing reliability and various forms of validity including discriminant and criterion validity, we add 
to the conceptual richness of i-deals as well as understanding of the dynamics that underpin the effective functioning and use of i-deals in the contemporary workplace. In sum, our study shows that beyond timing and content of i-deals, motives for i-deal negotiation matters in relation to various outcomes, and that i-deal management is an important contextual factor that may determine the effectiveness of i-deals in organizations. Future research may shed more light upon the dynamics of these new measures in the workplace. 


\section{References}

Allen, S., \& Ortlepp, K. (2002). Conceptualising and operationalising work versus career salience. SA Journal of Industrial Psychology, 28, 7-14. https://doi.org/10.4102/sajip.v28i2.45/.

Anand, S., Vidyarthi, P. R., Liden, R. C., \& Rousseau, D. M. (2010). Good citizens in poorquality relationships: Idiosyncratic deals as a substitute for relationship quality. Academy of Management Journal, 53(5), 970-988. https://doi.org/10.5465/amj.2010.54533176.

Avolio, B. J., \& Bass, B. M. (1995). Individual consideration viewed at multiple levels of analysis: A multi-level framework for examining the diffusion of transformational leadership. The Leadership Quarterly, 6, 199-218. https://doi.org/10.1016/10489843(95)90035-7

Bal, P.M. (2017). Why do employees negotiate idiosyncratic deals? An exploration of the process of i-deal negotiation. New Zealand Journal of Employment Relations, 42, 2-18.

Bal, P. M., De Jong, S. B., Jansen, P. G., \& Bakker, A. B. (2012). Motivating employees to work beyond retirement: A multi-level study of the role of I-deals and unit climate. Journal of Management Studies, 49, 306-331. https://doi.org/10.1111/j.14676486.2011.01026.x.

Bal, P. M., \& Dorenbosch, L. (2015). Age-related differences in the relations between individualised HRM and organisational performance: a large-scale employer survey. Human Resource Management Journal, 25, 41-61. https://doi.org/10.1111/17488583.12058.

Bal, P. M., \& Jansen, P. G. (2016). Workplace flexibility across the lifespan. Research in Personnel and Human Resources Management, 34, 43-99. https://doi.org/10.1108/s0742730120160000034009. 
Bal, P. M., \& Lub, X. D. (2016). Individualization of work arrangements. In M. Bal \& D. M. Rousseau (Eds.), Idiosyncratic deals between employees and organizations. New York: Routledge. https://doi.org/10.4324/9781315771496-2.

Bal, P.M., \& Rousseau, D. M. (2015). Idiosyncratic Deals between Employees and Organizations: Conceptual Issues, Applications and the Role of Co-workers (eds.). London: Psychology Press. https://doi.org/10.4324/9781315771496.

Bass, B.M., \& Avolio, B.J. (1997). Multifactor Leadership Questionnaires: Technical Report, Leader Form, Rater Form, and Scoring Key for MLQ Form 5Z-Short (2nd ed.). Mind Garden, Redwood City, CA. https://doi.org/10.1037/t12078-000.

Breaugh, J. A. (1989). The Work Autonomy scale; additional validity evidence. Human Relations, 42, 1033-1056. https://doi.org/10.1177/001872678904201105.

Brett, J., \& Thompson, L. (2016). Negotiation. Organizational Behavior and Human Decision Processes, 136, 68-79. https://doi.org/10.1016/j.obhdp.2016.06.003.

Brockner, J., \& Higgins, E. T. (2001). Regulatory focus theory: Implications for the study of emotions at work. Organizational Behavior and Human Decision Processes, 86, 35-66. https://doi.org/10.1006/obhd.2001.2972.

Broschak, J. P., \& Davis-Blake, A. (2006). Mixing standard work and nonstandard deals: The consequences of heterogeneity in employment arrangements. Academy of Management Journal, 49, 371-393. https://doi.org/10.5465/amj.2006.20786085.

Bryant, F. B. King, S. P., \& Smart, C.M. (2007). Multivariate statistical strategies for construct validation in positive psychology. In: Ong, A. G. \& van Dulmen, M. (Eds.), Oxford handbook of methods in positive psychology (pp. 61-82). Oxford: Oxford University Press. 
Costello, A. B., \& Osborne, J. W. (2005). Best practices in exploratory factor analysis : Four recommendations for getting the most from your analysis. Practical Assessment, Research \& Education, 10, 1-9. https://doi.org/10.4135/9781412995627.d8.

Farh, J. L., Tsui, A. S., Xin, K., \& Cheng, B. S. (1998). The influence of relational demography and guanxi: The Chinese case. Organization Science, 9, 471-488. https://doi.org/10.1287/orsc.9.4.471.

Floyd, F. J., \& Widaman, K. F. (1995). Factor analysis in the development and refinement of clinical assessment instruments. Psychological Assessment, 7, 286-299. https://doi.org/10.1037//1040-3590.7.3.286.

Gascoigne, C., \& Kelliher, C. (2018). The transition to part-time: How professionals negotiate 'reduced time and workload' i-deals and craft their jobs. Human Relations, 71, 103-125. https://doi.org/10.1177/0018726717722394.

Greenberg, J., Roberge, M. E., Ho, V. T., \& Rousseau, D. M. (2004). Fairness as an “i-deal”: Justice in under-the-table employment arrangements. Research in Personnel and Human Resources Management, 22, 1-34. https://doi.org/10.1016/s0742-7301(04)23001-8.

Hinkin, T. R. (1998). A brief tutorial on the development of measures for use in survey questionnaires. Organizational Research Methods, 1, 104-121. https://doi.org/10.1177/109442819800100106.

Ho, V. T., \& Kong, D. T. (2015). Exploring the signaling function of idiosyncratic deals and their interaction. Organizational Behavior and Human Decision Processes, 131, 149161. https://doi.org/10.1016/j.obhdp.2015.08.002.

Hornung, S., Rousseau, D. M., \& Glaser, J. (2008). Creating flexible work arrangements through idiosyncratic deals. Journal of Applied Psychology, 93, 655-664. https://doi.org/10.1037/0021-9010.93.3.655. 
Hornung, S., Rousseau, D. M., \& Glaser, J. (2009). Why supervisors make idiosyncratic deals: Antecedents and outcomes of i-deals from a managerial perspective. Journal of Managerial Psychology, 24, 738-764. https://doi.org/10.1108/02683940910996770.

Hornung, S., Rouseau, D. M., Glaser, J., Angerer, P., \& Weigl, M. (2011). Employeeoriented leadership and quality of working life: Mediating roles of idiosyncratic deals. Psychological Reports, 108, 59-74. https://doi.org/10.2466/07.13.14.21.pr0.108.1.59-74.

Kooij, D. T., Jansen, P. G., Dikkers, J. S., \& de Lange, A. H. (2014). Managing aging workers: A mixed methods study on bundles of HR practices for aging workers. The International Journal of Human Resource Management, 25, 2192-2212. https://doi.org/10.1080/09585192.2013.872169.

Kristof-Brown A. L., Zimmerman R. D., \& Johnson E. C. (2005). Consequences of individuals' fit at work: A meta-analysis of person-job, person-organization, persongroup, and person-supervisor fit. Personnel Psychology 58, 281-342. https://doi.org/10.1111/j.1744-6570.2005.00672.x.

Liao, C., Wayne, S. J., \& Rousseau, D. M. (2016). Idiosyncratic deals in contemporary organizations: A qualitative and meta-analytical review. Journal of Organizational Behavior, 37, S9-S29. https://doi.org/10.1002/job.1959.

Marescaux, E., \& De Winne, S. (2015). Equity versus need: how do coworkers judge the distributive fairness of i-deals? In: P.M. Bal \& D.M. Rousseau (eds.), Idiosyncratic Deals Between Employees and Organizations: Conceptual Issues, Applications and the Role of Co-workers, pp. 107-121. London: Psychology Press. https://doi.org/10.4324/9781315771496-8.

Martin, K., \& Freeman, R. E. (2003). Some problems with employee monitoring. Journal of Business Ethics, 43, 353-361. https://doi.org/10.2139/ssrn.348040. 
Meade, A. W., Johnson, E. C., \& Braddy, P. W. (2008). Power and sensitivity of alternative fit indices in tests of measurement invariance. Journal of Applied Psychology, 93, 568592. https://doi.org/10.1037/0021-9010.93.3.568.

Muthén, L. K., \& Muthén, B. O. (2015). Mplus. Statistical analysis with latent variables. Version 7.4. Los Angeles, CA: Muthén \& Muthén.

Morrison, E. W., \& Phelps, C. C. (1999). Taking charge at work: Extrarole efforts to initiate workplace change. Academy of Management Journal, 42, 403-419. https://doi.org/10.2307/257011.

Nauta, A., \& van de Ven, C. (2015). An i-deal career. In: P.M. Bal \& D.M. Rousseau (eds.), Idiosyncratic Deals Between Employees and Organizations: Conceptual Issues, Applications and the Role of Co-workers, pp. 65-72. London: Psychology Press. https://doi.org/10.4324/9781315771496-5.

Nielsen, K., \& Abildgaard, J. S. (2012). The development and validation of a job crafting measure for use with blue-collar workers. Work and Stress, 26, 365-384. https://doi.org/10.1080/02678373.2012.733543.

Ng, T. W., \& Lucianetti, L. (2016). Goal striving, idiosyncratic deals, and job behavior. Journal of Organizational Behavior, 37, 41-60. https://doi.org/10.1002/job.2023.

Reif, J. A., \& Brodbeck, F. C. (2014). Initiation of negotiation and its role in negotiation research: Foundations of a theoretical model. Organizational Psychology Review, 4, $363-$ 381. https://doi.org/10.1177/2041386614547248.

Rioux, S. M., \& Penner, L. A. (2001). The causes of organizational citizenship behavior: a motivational analysis. Journal of Applied Psychology, 86, 1306-1314. https://doi.org/10.1037//0021-9010.86.6.1306. 
Rosen, C. C., Slater, D. J., \& Johnson, R. E. (2013). Let's make a deal development and validation of the ex post I-deals scale. Journal of Management, 39, 709-742. https://doi.org/10.1177/0149206310394865.

Rousseau, D. M. (2005). I-deals, idiosyncratic Deals Employees Bargain for Themselves. New York: ME Sharpe. https://doi.org/10.4324/9781315703589.

Rousseau, D. M., Ho, V. T., \& Greenberg, J. (2006). I-deals: Idiosyncratic terms in employment relationships. Academy of Management Review, 31, 977-994. https://doi.org/10.5465/amr.2006.22527470.

Rousseau, D. M., Hornung, S., \& Kim, T. G. (2009). Idiosyncratic deals: Testing propositions on timing, content, and the employment relationship. Journal of Vocational Behavior, 74, 338-348. https://doi.org/10.1016/j.jvb.2009.02.004.

Rowan, N., \& Wulff, D. (2007). Using qualitative methods to inform scale development. The Qualitative Report, 12, 450-466.

Schaufeli, W. B., \& Bakker, A. B. (2004). Job demands, job resources, and their relationship with burnout and engagement: A multi-sample study. Journal of Organizational Behavior, 25, 293-315. https://doi.org/10.1002/job.248.

Shaffer, J. A., DeGeest, D., \& Li, A. (2016). Tackling the problem of construct proliferation: A guide to assessing the discriminant validity of conceptually related constructs. Organizational Research Methods, 19, 80-110. https://doi.org/10.1177/1094428115598239.

Wayne, S. J., Shore, L. M., \& Liden, R. C. (1997). Perceived organizational support and leader-member exchange: A social exchange perspective. Academy of Management Journal, 40, 82-111. https://doi.org/10.2307/257021. 
Wu, C. H., Griffin, M. A., \& Parker, S. K. (2015). Developing agency through good work: Longitudinal effects of job autonomy and skill utilization on locus of control. Journal of Vocational Behavior, 89, 102-108. https://doi.org/10.1016/j.jvb.2015.05.004. 
Table 1: Exploratory Factor Analysis Results for the I-deal Motives and Management Scales (Study 1)

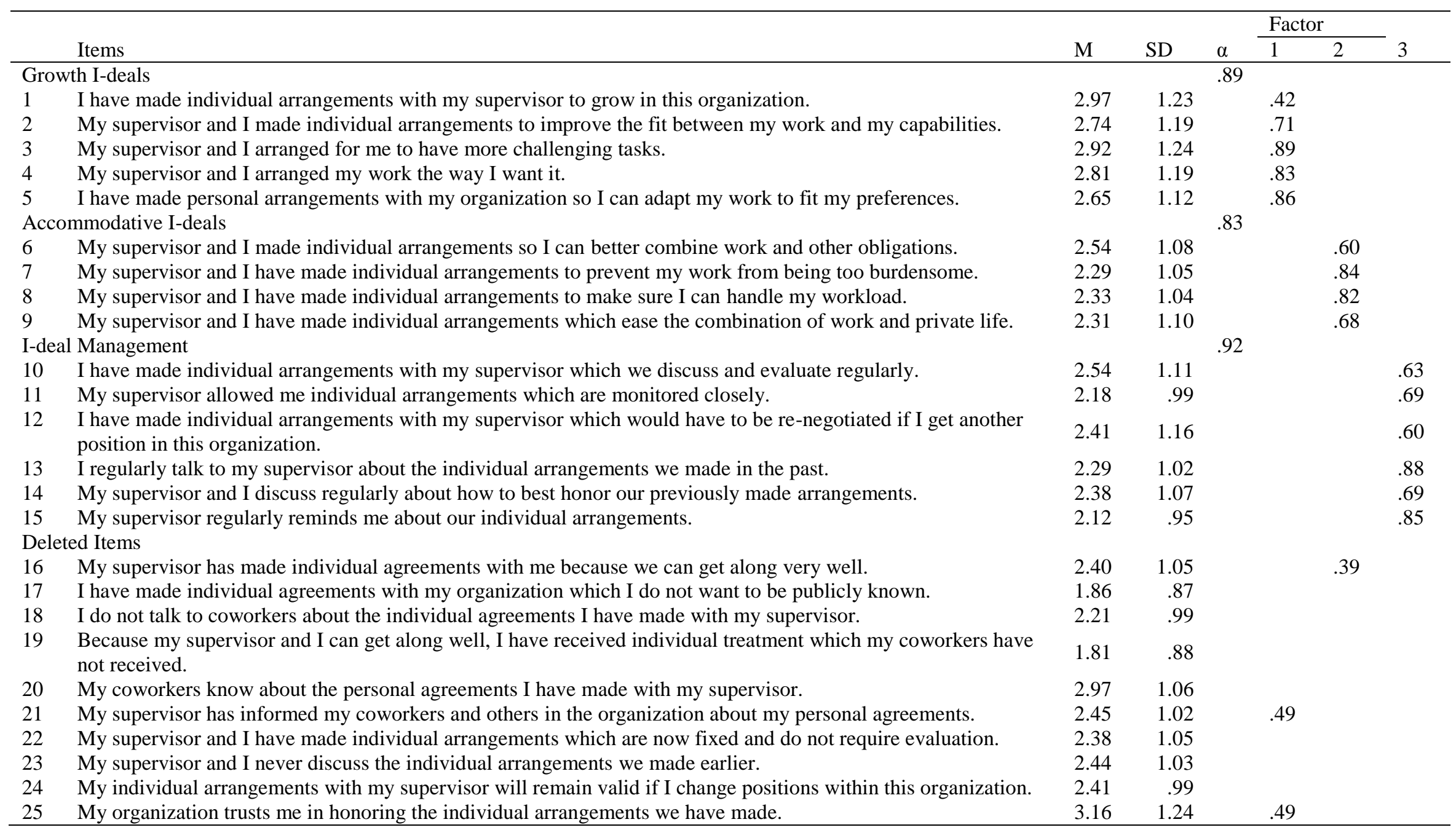

Note: $\mathrm{N}=108$. Factor loadings $>.39$ are reported. 
Table 2: Means, Standard Deviations, Cronbach's alphas and Correlations among the Variables (Study 1).

\begin{tabular}{llrrrrrrr}
\hline & Variable & $M$ & $S D$ & 1 & 2 & 3 & 4 & 5 \\
\hline 1 & Ex-ante I-deals & 2.14 & 1.10 & $\mathbf{. 8 2}$ & & & & \\
2 & Ex-post I-deals & 2.55 & 1.12 & $.66^{* *}$ &. $\mathbf{7 4}$ & & & \\
3 & Growth I-deals & 2.82 & 1.00 & $.31^{* *}$ & $.46^{* *}$ & $\mathbf{. 8 9}$ & & \\
4 & Accommodative I-deals & 2.37 & .87 & .17 & $.32^{* *}$ & $.49^{* *}$ & $\mathbf{. 8 3}$ & .92 \\
5 & I-deal Management & 2.32 & .89 & $.37^{* *}$ & $.49^{* *}$ & $.72^{* *}$ & $.52^{* *}$ & $\mathbf{. 9 2}$ \\
\hline
\end{tabular}

Note. Cronbach's alphas are reported along the diagonal. $N=108 .{ }^{*} p<.05 ;{ }^{* *} p<.01$. 
Table 3: Confirmatory factor analyses of the i-deals scales for Study 2 and Study 3.

\begin{tabular}{|c|c|c|c|c|c|c|}
\hline Variable & $\chi^{2}$ & $d f$ & $\chi^{2} / d f$ & CFI & RMSEA & SRMR \\
\hline \multicolumn{7}{|l|}{ Study 2: Test of Validity of New Measures } \\
\hline 3-factor (baseline model) & $129.85 * * *$ & 75 & 1.73 & .94 & .08 & .06 \\
\hline 2-factor (growth and accommodative i-deals loading on one factor) & $161.64 * * *$ & 77 & 2.10 & 91 & .10 & .07 \\
\hline 1-factor (all items loading on one factor) & $292.55 * * *$ & 78 & 3.75 & .76 & .15 & .10 \\
\hline \multirow{2}{*}{\multicolumn{7}{|c|}{$\begin{array}{l}\text { Study 2: Test of Discriminant Validity of New Measures against the } \\
\text { Content Measures (Rosen et al., 2012) }\end{array}$}} \\
\hline & & & & & & \\
\hline 7-factor (baseline model) & $586.60 * * *$ & 401 & 1.46 & .91 & .06 & .07 \\
\hline 6-factor (growth and accommodative i-deals loading on one factor) & $637.96 * * *$ & 407 & 1.57 & .89 & .07 & .08 \\
\hline 6-factor (flexibility and location i-deals loading on one factor) & $676.07 * * *$ & 407 & 1.66 & .87 & .07 & .09 \\
\hline 6-factor (growth and task i-deals loading on one factor) & $755.66 * * *$ & 407 & 1.86 & .84 & .08 & .10 \\
\hline $\begin{array}{l}6 \text {-factor (accommodative and flexibility i-deals loading on one } \\
\text { factor) }\end{array}$ & $649.89 * * *$ & 407 & 1.60 & .89 & .07 & .08 \\
\hline $\begin{array}{l}5 \text {-factor (growth, accommodative i-deals, and i-deals management } \\
\text { loading on one factor) }\end{array}$ & $791.03 * * *$ & 412 & 1.92 & .82 & .09 & .10 \\
\hline $\begin{array}{l}\text { 4-factor (task, flexibility, location, and financial i-deals loading on } \\
\text { one factor) }\end{array}$ & $1131.86 * * *$ & 416 & 2.72 & .66 & .12 & .12 \\
\hline $\begin{array}{l}2 \text { factors (growth, accommodative i-deals, and i-deals management } \\
\text { loading on one factor; task, flexibility, location, and financial i- } \\
\text { deals loading on one factor) }\end{array}$ & $1296.74 * * *$ & 421 & 3.07 & .59 & .13 & .13 \\
\hline 1-factor (all items loading on one factor) & $1546.85 * * *$ & 422 & 3.67 & .47 & .15 & .15 \\
\hline \multicolumn{7}{|l|}{ Study 3: Test of Validity of New Measure } \\
\hline 3-factor (baseline model) & $175.19 * * *$ & 75 & 2.34 & .92 & .07 & .07 \\
\hline 2-factor (growth and accommodative i-deals loading on one factor) & $212.93 * * *$ & 77 & 2.77 & .89 & .11 & .08 \\
\hline 1-factor (all items loading on one factor) & $327.24 * * *$ & 78 & 4.20 & .79 & .15 & .08 \\
\hline
\end{tabular}

Note: ${ }^{* * * *} p<.001$. For each alternative model, it is indicated which items are modeled to load on one factor. 
Table 4: Means, Standard Deviations, Cronbach's alphas and Correlations among the Variables (Study 2).

\begin{tabular}{|c|c|c|c|c|c|c|c|c|c|c|}
\hline & Variable & $M$ & $S D$ & 1 & 2 & 3 & 4 & 5 & 6 & 7 \\
\hline 1 & Task I-deals & 3.19 & .92 & .89 & & & & & & \\
\hline 2 & Flexibility I-deals & 3.19 & .99 & $.54 * *$ & .70 & & & & & \\
\hline 3 & Location I-deals & 2.43 & 1.13 & $.42 * *$ & $.36^{* *}$ & .81 & & & & \\
\hline 4 & Financial I-deals & 2.43 & 1.11 & $.31 * *$ & .09 & $.44 * *$ & .93 & & & \\
\hline 5 & Growth I-deals & 3.02 & .86 & $.48 * *$ & $.38 * *$ & $.26 * *$ & .14 & .86 & & \\
\hline 6 & Accommodative I-deals & 2.71 & .95 & $.31 * *$ & $.53 * *$ & .17 & .13 & $.59 * *$ & .79 & \\
\hline 7 & I-deal Management & 2.37 & .85 & $.19 *$ & $.19 *$ & $.24 * *$ & $.39 * *$ & $.45^{* *}$ & $.48 * *$ & .86 \\
\hline
\end{tabular}


Table 5: Means, Standard Deviations, Cronbach's alphas and Correlations among the Variables (Study 3).

\begin{tabular}{|c|c|c|c|c|c|c|c|c|c|c|}
\hline & Variable & $M$ & $S D$ & 1 & 2 & 3 & 4 & 5 & 6 & 7 \\
\hline 1 & $\begin{array}{l}\text { Transformational } \\
\text { Leadership }\end{array}$ & 3.48 & .66 & .88 & & & & & & \\
\hline 2 & Autonomy & 5.22 & 1.42 & $.23 * *$ & .93 & & & & & \\
\hline 3 & Work Engagement & 3.59 & .84 & $.39 * *$ & $.39 * *$ & .89 & & & & \\
\hline 4 & Turnover Intention & 4.12 & 1.61 & $-.40 * *$ & $-.29 * *$ & $-.49 * *$ & .86 & & & \\
\hline 5 & Growth I-deals & 3.06 & .77 & $.57 * *$ & $.32 * *$ & $.40 * *$ & $-.24 * *$ & .78 & & \\
\hline 6 & $\begin{array}{l}\text { Accommodative I- } \\
\text { deals }\end{array}$ & 3.02 & .98 & $.45 * *$ & .11 & $.22 * *$ & -.13 & $.62 * *$ & .89 & \\
\hline 7 & $\begin{array}{l}\text { I-deal } \\
\text { Management }\end{array}$ & 2.78 & .78 & $.39 * *$ & -.02 & .15 & -.08 & $.56 * *$ & $.61 * *$ & .86 \\
\hline
\end{tabular}

Note. Cronbach's alphas are reported along the diagonal. $N=153 .{ }^{*} p<.05 ;{ }^{* *} p<.01$. 
Table 6: Results for Regression Analyses on Outcomes of I-deals (Study 3).

\begin{tabular}{|c|c|c|c|}
\hline & Work Engagement & Turnover Intention & Autonomy \\
\hline & $\beta$ & $\beta$ & $\beta$ \\
\hline Growth I-deals & $.46^{* * *}$ & $-.29 * *$ & $.50 * * *$ \\
\hline Accommodative I-deals & .01 & .00 & -.04 \\
\hline I-deal Management & -.11 & .08 & $-.28 * *$ \\
\hline $\mathrm{F}$ & $10.02 * * *$ & $3.31 *$ & $9.61 * * *$ \\
\hline Adjusted $\mathrm{R}^{2}$ & .15 & .04 & .15 \\
\hline$\Delta \mathrm{R}^{2}$ & $.17^{1}$ & $.06^{1}$ & $.16^{1}$ \\
\hline
\end{tabular}

Note. $N=153 .{ }^{*} p<.05 ;{ }^{* *} p<.01 ;{ }^{* * *} p<.001 .{ }^{1}$ Comparison to a null-model with no predictors. 
Table 7: Means, Standard Deviations, Cronbach's alphas and Correlations among the Variables (Study 4).

\begin{tabular}{|c|c|c|c|c|c|c|c|c|c|c|c|c|c|c|c|c|c|c|}
\hline & Variable & Time & $M$ & $S D$ & 1 & 2 & 3 & 4 & 5 & 6 & 7 & 8 & 9 & 10 & 11 & 12 & 13 & 14 \\
\hline 1 & Ex-ante I-deals & $\mathrm{T} 1$ & 2.24 & 1.17 & .83 & & & & & & & & & & & & & \\
\hline 2 & Ex-post I-deals & $\mathrm{T} 1$ & 3.32 & 1.26 & $.24 * *$ & .92 & & & & & & & & & & & & \\
\hline 3 & $\begin{array}{l}\text { Transformational } \\
\text { Leadership }\end{array}$ & $\mathrm{T} 1$ & 3.46 & .86 & $.11 *$ & $.27 * *$ & .93 & & & & & & & & & & & \\
\hline 4 & Career Orientation & $\mathrm{T} 1$ & 2.78 & .90 & $.14 * *$ & .02 & $.32 * *$ & .91 & & & & & & & & & & \\
\hline 5 & $\begin{array}{l}\text { Satisfaction with I- } \\
\text { deals }\end{array}$ & $\mathrm{T} 1$ & 3.69 & 1.04 & $.16^{* *}$ & $.60 * *$ & $.48 * *$ & $.17 * *$ & .93 & & & & & & & & & \\
\hline 6 & Work Engagement & $\mathrm{T} 2$ & 4.72 & 1.38 & $.11^{*}$ & $.17 * *$ & $.45^{* *}$ & $.43^{* *}$ & $.35^{* *}$ & .95 & & & & & & & & \\
\hline 7 & Turnover Intention & $\mathrm{T} 2$ & 2.78 & 1.23 & -.03 & $-.19 * *$ & $-.40 * *$ & $-.16 * *$ & $-.33 * *$ & $-.54 * *$ & .91 & & & & & & & \\
\hline 8 & Initiative Taking & $\mathrm{T} 2$ & 3.54 & .74 & $.19 * *$ & $.21 * *$ & $.19 * *$ & $.26 * *$ & $.14 * *$ & $.28 * *$ & $-.10 *$ & .91 & & & & & & \\
\hline 9 & Growth I-deals & $\mathrm{T} 1$ & 2.90 & .97 & $.32 * *$ & $.52 * *$ & $.42 * *$ & $.32 * *$ & $.46 * *$ & $.33 * *$ & $-.18 * *$ & $.29 * *$ & .85 & & & & & \\
\hline 10 & $\begin{array}{l}\text { Accommodative I- } \\
\text { deals }\end{array}$ & $\mathrm{T} 1$ & 2.58 & 1.07 & $.29 * *$ & $.42 * *$ & $.32 * *$ & $.15^{* *}$ & $.39 * *$ & $.20 * *$ & $-.11 *$ & $.15 * *$ & $.67 * *$ & .86 & & & & \\
\hline 11 & I-deal Management & $\mathrm{T} 1$ & 2.22 & .97 & $.31 * *$ & $.28 * *$ & $.36^{* *}$ & $.31 * *$ & $.23^{* *}$ & $.28 * *$ & $-.12 *$ & $.20 * *$ & $.64 * *$ & $.64 * *$ & .89 & & & \\
\hline 12 & Growth I-deals & $\mathrm{T} 2$ & 2.63 & 1.02 & $.25 * *$ & $.34 * *$ & $.39 * *$ & $.29 * *$ & $.33 * *$ & $.42 * *$ & $-.26^{* *}$ & $.29 * *$ & $.64 * *$ & $.46^{* *} *$ & $.48 * *$ & .88 & & \\
\hline 13 & $\begin{array}{l}\text { Accommodative I- } \\
\text { deals }\end{array}$ & $\mathrm{T} 2$ & 2.55 & 1.12 & $.21 * *$ & $.34 * *$ & $.35 * *$ & $.19 * *$ & $.33 * *$ & $.36 * *$ & $-.25^{* *}$ & $.22 * *$ & $.53 * *$ & $.63 * *$ & $.53 * *$ & $.72 * *$ & .91 & \\
\hline 14 & I-deal Management & $\mathrm{T} 2$ & 2.13 & .97 & $.27 * *$ & $.21 * *$ & $.30 * *$ & $.27 * *$ & $.19 * *$ & $.34 * *$ & $-.13 * *$ & $.24 * *$ & $.50 * *$ & $.50 * *$ & $.66^{* *}$ & $.65^{* *}$ & $.68 * *$ & .92 \\
\hline
\end{tabular}

Note. Cronbach's alphas are reported along the diagonal. $N=427 .{ }^{*} p<.05 ;{ }^{* *} p<.01$. 
Table 8: Results for Regression Analyses on Predictors of I-deals (Study 4).

\begin{tabular}{lccc}
\hline & $\begin{array}{c}\text { Growth } \\
\text { I-deals T2 }\end{array}$ & Accom. I-deals T2 & I-deal Management T2 \\
\hline \multicolumn{1}{c}{$\beta$} & $\beta$ & $\beta$ \\
\hline $\begin{array}{l}\text { Transformational } \\
\text { Ceadership T1 }\end{array}$ & $.33^{* * *}$ & $.32^{* * *}$ & $.24 * * *$ \\
T1 & $.18^{* * *}$ & .09 & $.19^{* * *}$ \\
& & & \\
$\mathrm{~F}$ & $47.05^{* * *}$ & $30.82^{* * *}$ & $29.57^{* * *}$ \\
Adjusted $\mathrm{R}^{2}$ & .18 & .12 & .12 \\
$\Delta \mathrm{R}^{2}$ & $.18^{1}$ & $.13^{1}$ & $.12^{1}$ \\
\hline Note. $N=427 .{ }^{*} p<.05 ;{ }^{* *} p<.01 ;{ }^{* * *} p<.001$. & \\
& &
\end{tabular}


Table 9: Results for Regression Analyses on Outcomes of I-deals (Study 4).

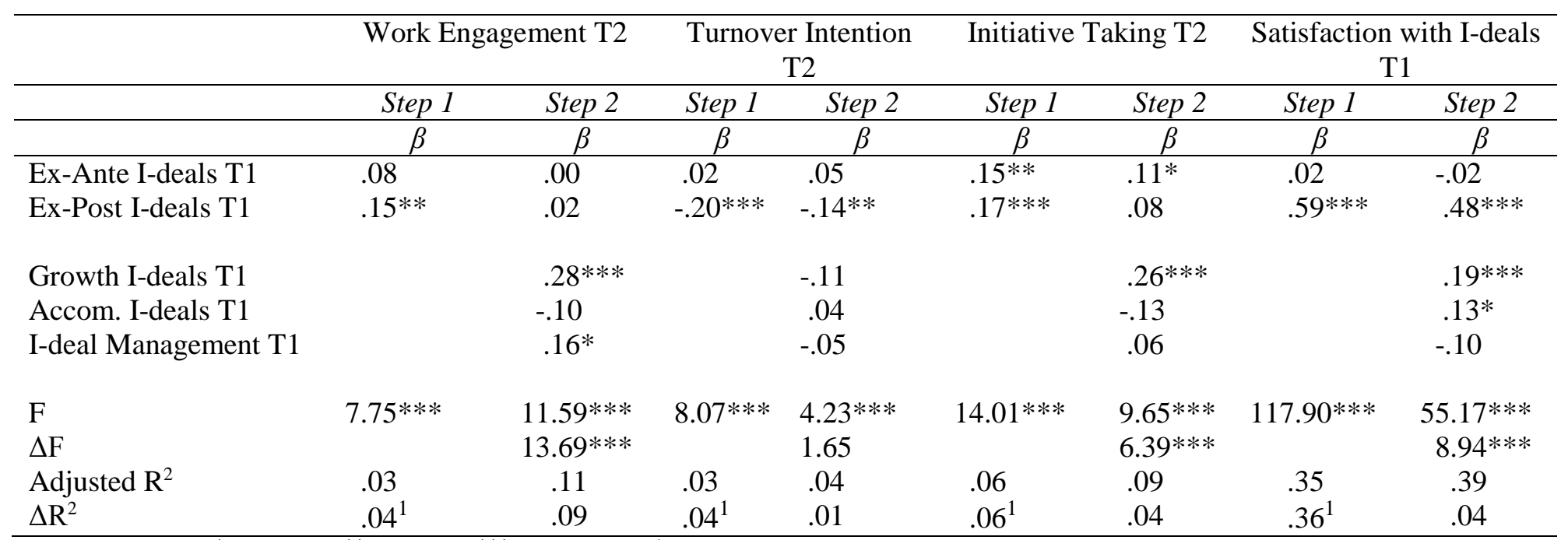

Note. $N=427 .{ }^{*} p<.05 ;{ }^{* * *} p<.01 ;{ }^{* * *} p<.001 .{ }^{1}$ Comparison to a null-model with no predictors. Accom. Ideals = Accommodative I-deals. 
